\title{
Panorama y canon en la enseñanza de la gramática española en Colombia durante el siglo XIX
}

\author{
Panorama and canon in the teaching of spanish grammar in \\ Colombia during the XIX century
}

María Martínez-Atienza de Dios*

\section{RESUMEN}

Constituye nuestro objeto de estudio el análisis de la enseñanza de la gramática española en las escuelas de Colombia del siglo XIX. Para ello, nos hemos basado en un corpus de obras publicadas en el país entre 1826 y 1889, que tuvieron una notable influencia en la educación de la materia que nos ocupa. Hemos analizado las doctrinas gramaticales presentes en las obras, de acuerdo con la teoría del canon de Zamorano Aguilar. Para ello, estudiamos las referencias en las portadas a autores considerados fundamentales, así como la información contenida en los paratextos. A las citas explícitas del canon, sumamos las referencias implícitas, que encontramos en el análisis de la morfología y de la sintaxis. Hemos comprobado que existe una evolución en la doctrina gramatical y que, desde el punto de vista teóricometodológico, pueden establecerse cuatro tendencias.

\section{ABSTRACT}

Our object of study is the analysis of the teaching of Spanish grammar in 19th century Colombian schools. To do this, we have based on a corpus of works published in the country between
Palabras clave: canon, Colombia, enseñanza de la gramática española, historiografía lingüística, siglo XIX.

Keywords: canon, Colombia, linguistic

Este trabajo se inscribe en el marco del proyecto HISPANAGRAMA “Las ideas gramaticales en la América del Pacífico y El Caribe (1800-1950): fuentes, focos, series textuales y canon" [FFI2017-86335-P] del MINECO, Plan Estatal de Investigación Científica y Técnica y de Innovación, cuyos investigadores principales son Alfonso Zamorano Aguilar (IP1) y Esteban T. Montoro del Arco (IP2) y de cuyo equipo investigador forma parte la autora del presente artículo.

** Española. Doctora en Ciencias del Lenguaje por la Universidad Ca' Foscari (Venecia). Profesora titular de la Universidad de Córdoba, Córdova, España. mmartinezatienza@uco.es 
1826 and 1889, which had a notable influence on the education of the subject at hand. We have analyzed the grammatical doctrines present in the works, in accordance with the canon theory (Zamorano Aguilar). To do this, we study the references on the covers to authors considered fundamental, as well as the information contained in the paratexts. To the explicit citations of the canon, we add the implicit references, which we find in the analysis of morphology and syntax. We have verified that there is an evolution in grammatical doctrine and that, from the theoretical-methodological point of view, four trends can be established. historiography, teaching of Spanish grammar, 19th century. 


\section{Introducción}

En Colombia se le ha concedido una notable importancia a la enseñanza de la gramática, en particular tras la independencia de España. El conocimiento de la lengua se asociaba con el concepto de unidad nacional (Jiménez Ángel, 2018), y se buscó el alfabetismo universal, potenciado por los distintos dirigentes (Orlando Melo, 2006). En efecto, el hecho de que varios presidentes de Colombia fueran, a su vez, gramáticos y autores de obras para la enseñanza, desempeñó sin duda un papel determinante (Agudelo Gil, 2014).

Como ha estudiado Uzcátegui (2010), desde 1821 hasta 1870 la educación en Colombia pretendió la separación de la formación colonialista, que había estado presente antes de 1810. Se vio en la escuela un modo de superar las condiciones políticas y culturales del período colonial. La promulgación de dos leyes educativas fue fundamental para crear las bases de la formación tras este período: 1) Ley sobre Establecimiento de Escuelas de Primeras Letras para niños de ambos sexos, de 6/08/1821, en la que se presta especial atención a la formación primaria; 2) Ley sobre Organización y arreglo de la Instrucción Pública, de 18/03/1826, que promueve la expansión de la instrucción en todo el territorio. Estas leyes supusieron "los primeros fundamentos -especialmente políticos- de la instrucción pública republicana de carácter oficial, que se mantendrá (...) en toda la legislación y sentencias oficiales y oficiosas durante el siglo XIX, por lo menos hasta 1870" (Uzcátegui, 2010, p. 189).

Por otro lado, cabe destacar que en este período, como demostraremos, las gramáticas de la Academia, de Vicente Salvá y de Andrés Bello ejercieron una destacada influencia en los distintos autores de las obras publicadas tras la época colonial y los encontramos citados en varias portadas. La Gramática de Salvá fue un referente en Hispanoamérica, en particular, en Colombia. Lliteras (1992) sostiene que las distintas ediciones de su obra "se difundieron antes y con mejor fortuna en América que en España" (p. 29).

Por lo que respecta a Bello, comprobaremos que a partir de la publicación de su Gramática en 1847, el autor aparece citado en numerosas ocasiones lo que se corresponde, además, con la influencia que ejerció en la doctrina gramatical de las obras. Uno y otro gramático constitu- 
yeron en el siglo XIX en Colombia un referente para la enseñanza de la materia en las escuelas.

\section{Marco teórico y metodológico}

Partimos del desarrollo de los objetivos de la historiografía lingüística desde la teoría de la comunicación, según la hipótesis de Zamorano Aguilar (2012). De acuerdo con ello se pueden distinguir varias subdisciplinas en función del elemento de la comunicación en el que focalicen la atención: historiografía de la lingüística, centrada en el receptor; historia de la lingüística, en el emisor; historificación de las ideas lingüísticas, en el mensaje; gramaticografía y lexicografía histórica, en el canal; Meta-HL, en el código y disciplinas afines, en el contexto. Se unen a ello las relaciones que pueden establecerse entre las subdisciplinas, en función de las cuales el autor distingue entre historiografía de la lingüística interna, centrada en el receptor + mensaje; historia de la lingüística interna, en el emisor + mensaje; historia de la lingüística externa, en emisor + contexto; historiografía de la lingüística externa, en receptor + contexto; metahistoria de la lingüística, en emisor + código y metahistoria de la lingüística, en receptor + código (Brekle, 1986).

Aplicando esta hipótesis desde el punto de vista metodológico, nuestro trabajo estará centrado, por un lado, en las relaciones entre los autores de las obras que estudiamos (emisores) y el contexto, por tanto, historia de la lingüística externa; por otro lado, se centrará en las relaciones entre los emisores y los mensajes, esto es, historia de la lingüística interna.

Además, seguiremos también la teoría del canon, construida nuevamente a partir del modelo comunicativo (Zamorano Aguilar, 2010a). Nos centraremos en analizar el canon histórico interno, esto es, las fuentes que emplean los autores de las obras que constituyen nuestro corpus, que puede o no coincidir con lo que el citado estudioso denomina canon histórico externo: los gramáticos que en las distintas épocas se consideran referentes. Dentro del interno distinguiremos entre el explícito, es decir, las fuentes declaradas por los autores en sus obras, y el implícito o encubierto, las no declaradas que, sin embargo, han ejercido influencia en los textos. 


\section{Hipótesis de trabajo}

Partimos de la hipótesis de que en la enseñanza de la gramática en Colombia durante el siglo XIX puede establecerse una periodización en relación con el tipo de análisis teórico-metodológico que se lleva a cabo. Lo intentaremos demostrar mediante el estudio de diez obras publicadas a lo largo de este siglo, la más antigua de 1826 y la última de 1889. Suponemos que las de las primeras décadas del siglo, dado que corresponden al período poscolonial, estarían más influidas por las gramáticas publicadas en España, en particular por la Academia, dada la continuidad de la relación con la que había constituido la metrópoli hasta entonces. Sin embargo, en las últimas décadas la influencia de autores hispanoamericanos sería mayor, en especial, de Andrés Bello, como forma de reivindicación de lo autóctono.

Por otra parte, la legislación educativa a lo largo del siglo fue determinante para establecer las obras que debían utilizarse en las escuelas y los gramáticos que constituían un referente. Así pues, tendremos en cuenta esta información a la hora del análisis del corpus, pues, de acuerdo con nuestra hipótesis las obras que fueron adoptadas o que eran recomendadas en las escuelas influyeron, a su vez, en otras posteriores y, con ello, los gramáticos que constituían el canon explícito e implícito.

\section{Objetivos}

Presentamos, a continuación, los principales objetivos de nuestro trabajo, ordenados desde los más generales hasta los más particulares:

- Establecer una periodización en la enseñanza de la gramática del español en Colombia durante el siglo XIX.

- Analizar un corpus de obras publicadas en el mencionado país y destinadas a la enseñanza de la gramática, para conocer la influencia que pudieron ejercer, teniendo en cuenta que, de acuerdo con la legislación educativa, varias de ellas fueron adoptadas para su uso en las escuelas.

- Estudiar el canon explícito e implícito de las distintas obras, analizando las referencias tanto en la portada, como en los prólogos y a lo largo de las obras.

- Comprobar si, a partir del análisis del tratamiento de determinados temas de sintaxis y de morfología, se puede constatar una evolu- 
ción desde concepciones más latinizantes hasta otras influidas por la renovación doctrinal.

\section{Descripción del corpus}

Nuestro corpus está constituido por diez obras diseñadas para la enseñanza de la gramática en las escuelas de Colombia, cuyos datos están incluidos en el apartado de referencias bibliográficas. Entre los criterios seguidos figuran que las obras se hubieran publicado en el país (concretamente, ocho en Bogotá, una en Cartagena y otra en Socorro) durante el siglo XIX; además, hemos intentado abarcar prácticamente toda la centuria, con el objetivo de analizar una posible evolución teórico-metodológica.

Hemos buscado que fueran obras destinadas a la enseñanza de la gramática española, que en estos momentos a menudo incluye también ortografía, prosodia y métrica. Todos los autores son de nacionalidad colombiana, a excepción de José de Urcullu, español, y de Juan Vicente González, venezolano. Varios desempeñaron puestos en política y ejercieron influencia en la instrucción colombiana; haremos referencia a los datos biográficos que más nos interesan de acuerdo con los objetivos de nuestro trabajo.

Hemos intentado que las obras tuvieran cierta repercusión en la enseñanza de la gramática, como lo muestra el hecho de que varias fueran adoptadas en las escuelas de Colombia, lo que veremos con más detalle. Las obras gozaron, pues, de difusión y algunas contaron con más de una edición.

\section{Análisis del canon en el corpus}

Nos vamos a concentrar, a continuación, en analizar el canon explícito e implícito y, para ello, recorreremos las distintas obras del corpus siguiendo un orden cronológico. Estableceremos cuatro grupos, que corresponden a la doctrina seguida en cada uno y a la influencia de distintos gramáticos. La mayor parte de las referencias al canon son positivas, de modo que cuando figura alguna negativa, lo hemos indicado en el análisis.

Como hemos afirmado en el apartado del marco teórico y metodológico, analizamos en nuestro trabajo las relaciones entre el emisor y el 
contexto, por un lado, y entre el emisor y el mensaje, por otro, de ahí la importancia de conocer al primero, que en este caso son los autores de las obras objeto de nuestro estudio.

Respecto de la influencia que ejercieron los distintos gramáticos del canon, prestaremos especial atención a la información contenida en los prólogos de las obras, por un lado, y en el análisis del verbo, por otro, pues en las obras los distintos autores le prestan particular atención a esta categoría gramatical y ello nos permite obtener una información fundamental acerca del canon. Además, haremos referencia a otros aspectos de la morfología y de la sintaxis de las obras.

\section{La influencia académica y la tradición latina en las gramáticas de las primeras décadas del siglo XIX}

Las dos primeras obras de nuestro corpus, Santiago Arroyo (1826) y Anónimo (1833), están ligadas a la tradición académica. En el primer caso, no hay referencia alguna al canon explícito: solo se nombra a la Academia en el prólogo, pero con relación a la crítica que hace Arroyo respecto de la gestión de los gobiernos cuando no promueven la formación del pueblo. El autor manifiesta así su interés en la educación, lo que se correspondió con su carrera profesional: en el Departamento del Cauca fue subdirector de Instrucción Pública y perteneció a la Junta Curadora de la Educación de los niños, así como a la Academia Nacional de Colombia (González Corrales, 2020).

En la sección dedicada a la ortografía, Anónimo $(1833)^{1}$ defiende la necesidad de conocer las normas de la Academia de la lengua, que se basan en los principios de pronunciación, uso constante y origen. La estructura de esta segunda obra es erotemática.

Respecto de la doctrina lingüística, en ambas se establece una distinción entre una sintaxis natural o regular y una sintaxis figurada, que responde a una concepción del orden entre las palabras como reflejo

1 El autor del trabajo que citamos como Anónimo (1833), localizado en la Biblioteca Nacional de Colombia sin referencia al autor, es Diego Narciso Herranz y Quirós. La obra es una reedición de su gramática del español, que gozó de una destacada presencia en América durante la primera mitad del siglo XIX. El autor fue docente en el Colegio Académico del Noble Arte de Primeras Letras de España, donde se fijó el uso de la gramática y la ortografía académicas, que influyeron en la obra que aquí estudiamos (García Folgado 2007). 
del orden lógico, esto es, de la ordenación del propio pensamiento. De acuerdo con ello, la primera sintaxis es el reflejo de dicho orden lógico, mientras que la segunda supone un "desvío" y su objeto de estudio son las figuras retóricas, que constituyen una separación de las reglas que determinan el uso de la lengua según la lógica.

Arroyo $(1826)^{2}$ considera que las representaciones correspondientes a la sintaxis figurada tienen una finalidad estética de modo que, aun suponiendo un desvío, dan "gracia y ornato" al discurso; no en vano habla de sintaxis figurada o adornada. Eso sí, utiliza el uso como criterio de su legitimación. Para Anónimo (1833) la sintaxis figurada también queda legitimada por el uso, en particular por el de los "mejores autores".

Encontramos la distinción entre ambos tipos de sintaxis en numerosas ediciones de la gramática académica, desde el siglo XVIII hasta el XX: está presente desde la edición de 1771 hasta la de 1924 (Garrido Vílchez, 2010). Según nuestra hipótesis, estas gramáticas influyeron en las dos obras de las primeras décadas del siglo XIX. Por otro lado, estas son las únicas obras del corpus que establecen tal distinción, lo que demuestra - junto a otras diferencias que estudiaremos-, una evolución en la doctrina desde principios hasta finales del siglo XIX.

Michael (1970) defiende que la separación entre ambas sintaxis responde, precisamente, al origen común de esta disciplina con la lógica y la retórica (véase también Gómez Asencio, 2014) . $^{3}$

Por otra parte, ambas gramáticas muestran su cercanía con la tradición latina en la concepción de los casos, pues afirman que existen seis en español. Esta concepción nuevamente contrasta con algunas de las gramáticas de mediados del siglo XIX y con las de las últimas décadas

2 En la obra de este autor encontramos un salto de páginas, como se puede comprobar desde el propio índice: en la segunda parte de la obra, la sección dedicada a la concordancia inicia en la página 127 , sin embargo, la siguiente sección empieza en la 112, lo que puede generar confusión al buscar la información.

3 Un dato más sobre esta relación lo proporciona el hecho de que en España el Reglamento general de Instrucción pública, aprobado en 1821 por las Cortes liberales, estableciera como cátedras de segunda enseñanza las de gramática general y lógica (Calero Vaquera, 2009, p. 33). 
que defienden que, frente al latín, en español el caso queda reservado exclusivamente al pronombre.

En efecto, hasta que apareció la referencia explícita a los complementos en las gramáticas, lo que encontramos son referencias a los casos, una concepción, por tanto, muy ligada a la de las lenguas clásicas. Los cambios que se fueron produciendo no se restringían a la terminología, sino que supusieron una evolución desde una sintaxis basada en la linealidad hasta otra que concibe las relaciones jerárquicas entre los elementos lingüísticos (Calero Vaquera (2007). En esta evolución, desempeñó un papel fundamental el concepto de complemento de Andrés Bello.

Las dos obras de este primer grupo manifiestan, pues, la influencia de la tradición académica, por un lado, y la cercanía a la tradición latina, por otra.

La influencia de Vicente Salvá y de Andrés Bello en las gramáticas de mediados del siglo XIX

La primera obra de este segundo grupo, siguiendo un orden cronológico, es la de Ulpiano González (1848). Como hemos podido constatar, la influencia del autor valenciano en la obra de Ulpiano González es notable, así como las referencias explícitas en su obra (Guzmán Méndez et al., 2018; Jiménez Ángel, 2018).

Por otra parte, la obra de Ulpiano González fue recomendada como texto en las escuelas de Cundinamarca (Cardona, 2007), lo que pudo contribuir a su difusión, y con ello a la de Salvá. Afirma el gramático al final del prólogo que para hacer su obra ha consultado las gramáticas de Salvá y de Martínez López, los principios de ortología, prosodia y métrica de Bello y el Diccionario de la Academia. Declara que ha copiado íntegramente muchos pasajes cuando lo ha considerado oportuno. Sumado a esto, encontramos a lo largo de su obra referencias a Salvá (canon explícito), sobre todo a su gramática, aunque también al Diccionario. Respecto de esta última obra, Ulpiano critica a la Academia y dice que Salvá tiene mejor criterio, aun con errores. La labor del historiógrafo de la lingüística es analizar si, en efecto, este tipo de afirmaciones por parte de los autores son ciertas o corresponden más bien a una cuestión de canon prestigioso. Constituye, pues, uno de nuestros objetivos en el análisis del canon. 
Presenta en su obra la definición de gramática de Salvá y, posteriormente, la suya; entre ambas es evidente la cercanía ${ }^{4}$. Además, comprobamos que también sigue al valenciano en el análisis de las formas verbales, como constatamos en la terminología: critica la confusión terminológica en torno a los tiempos verbales y adopta la de Salvá, por lo que utiliza pretérito coexistente para pretérito imperfecto, pretérito absoluto para pretérito perfecto simple, futuro absoluto y futuro condicional ${ }^{5}$. Encontramos también algunos ejemplos del uso de las formas verbales que toma del gramático, como él mismo declara. Rebate en alguna ocasión su postura, como al hacer referencia a la conjugación de satisfacer, que según Salvá no sigue la de hacer.

En determinados fragmentos de la obra de Ulpiano González parece haber más bien un diálogo con las ideas de Salvá - a quien sigue también en la ortografía-, y elogia su criterio respecto de la acentuación: “¿Existe algo que sea más lógico y cómodo que el tratado de acentuación de Salvá?” (p. 138). No obstante, también es crítico con el gramático, como hemos visto en la conjugación de satisfacer, así como respecto de la excesiva benevolencia en la introducción de léxico de Hispanoamérica o en la ausencia en su Diccionario de determinados términos; sin embargo, declara la superioridad de esta obra por encima de las académicas:

No es esto decir que sea malo el Diccionario de Salvá: todo lo contrario, aun con este defecto, hijo de la mal entendida benevolencia del autor, en querer admitir a las repúblicas suramericanas a la comunión del idioma castellano, lo reputo mejor que todos los que corren por ahí de la Academia (p. 161).

4 Para un análisis de la concepción gramatical en Colombia durante el siglo XIX y, en particular, de la sintaxis, véase, respectivamente, Martínez-Atienza (en prensa a y en prensa b).

5 Como ha estudiado Lliteras (1992), Salvá (1988/ [1830-1847]) incluye el futuro condicional entre los tiempos de indicativo, aun sabiendo que rompía con la tradición precedente, que lo consideraba dentro del subjuntivo. Defiende la pertenencia al primer modo porque su origen perifrástico a partir del verbo haber es distinto al de cantara-cantase, que derivan de formas latinas; presenta al respecto argumentos de tipo sintáctico. Como demuestra Ridruejo (1985) (en Lliteras, 1992), tales argumentos fueron utilizados posteriormente por gramáticos como Gili Gaya, Hernández Alonso o Rojo. Además, defiende la estudiosa que la inclusión en el indicativo habría influido en la Gramática de Bello, y señala que con este cambio Salvá se inscribía en una tendencia desarrollada en la gramática francesa por lo menos desde el siglo XVIII. Véase también Peñalver (1992). 
Cita también a Martínez López, a veces elogiando su criterio y otras rechazándolo (canon negativo), y critica explícitamente en dos ocasiones el Catecismo de Urcullu, presente en nuestro corpus, a lo que se suma la crítica a Luis de Mata y Araujo, ambos autores coetáneos de Ulpiano González. En total, encontramos tres referencias a Martínez López, una de ellas en el apartado de puntuación, al decir que su modo para enseñarla le parece más claro que cualquier otro; 14 referencias a Salvá, dos de ellas en el apartado de la ortografía, una en el de la prosodia, donde presenta la oposición entre Salvá y la Academia. Entre estas referencias se incluye el elogio al Diccionario de Salvá por encima del académico.

El autor cuyo porcentaje de citas es mayor coincide con ser también el que más influencia ha ejercido en la obra de Ulpiano González (1848), como reflejamos en la Tabla 1).

Tabla 1

Canon explícito en la obra de Ulpiano González (1848)

\begin{tabular}{lcccc}
\hline Ubicación de las citas & Academia & Martínez López & Salvá & Bello \\
\hline Prólogo & 1 & 2 & & 1 \\
\hline Ortografía u ortología & 1 & 4 & 4 & 3 \\
\hline Morfología & & 1 & 8 & \\
\hline Sintaxis & & \multicolumn{3}{l}{1} \\
\hline Atención a la norma & $\mathbf{5}$ & 1 & 14 & \\
\hline Porcentaje de citas & $\mathbf{1 5 , 2 1 \%}$ & $17,39 \%$ & $58,69 \%$ & $8,69 \%$ \\
\hline
\end{tabular}

Fuente: Elaboración propia.

La segunda obra de este grupo corresponde a Santiago Pérez (1853), de origen colombiano, quien además de académico y autor de textos escolares como el que aquí analizamos, perteneció al partido liberal y fue presidente de los Estados Unidos de Colombia desde 1874 hasta 1876 (Agudelo Gil, 2014). Su compromiso con la educación lo demostró en la búsqueda de la mejora de la instrucción pública y en la fundación de escuelas en numerosas ciudades del país.

En la portada de su obra declara la influencia de varios gramáticos: "he procurado exponer metódicamente, y con la concisión compatible con la claridad, las doctrinas más bien recibidas de Salvá, Sicilia, Bello y Martínez López" (p. xx). No incluye prólogo ni intro- 
ducción a su obra. A pesar de que las referencias al canon explícito son escasas (Tabla 2), puesto que se reducen a las de la portada y a algunos ejemplos, manifiesta una influencia clara de la gramática de Bello, que constituiría canon implícito. En efecto, Jiménez Ángel (2018) lo considera introductor de las doctrinas gramaticales de Bello en Colombia. Comprobamos la influencia del autor venezolano en la terminología utilizada tanto para el análisis de los tiempos verbales de la conjugación como para las distintas estructuras sintácticas. Respecto de lo primero, Santiago Pérez presenta los cinco tiempos del indicativo con los siguientes términos: presente, copretérito, pretérito, futuro y pospretérito y, además, propone unas definiciones tanto de los tiempos como de los modos casi idénticas a las de Bello: "El presente expresa la coexistencia del atributo con el momento en que se expresa"; "El copretérito significa la simultaneidad del atributo con una cosa pasada" (p. 27). Además, siguiendo a Bello, afirma que el imperativo consta solo de un tiempo: el futuro. Respecto de la caracterización del indicativo, recoge: "El modo indicativo expresa los juicios en que se afirma un hecho como positivo o negativo, unas veces de una manera independiente y otras en una proposición incidente" ${ }^{\prime 6}$. Por otro lado, la caracterización de este modo difiere de la que encontramos en todos los gramáticos que preceden a Santiago Pérez en el corpus.

En sintaxis constatamos una terminología propia del gramático venezolano, como proposición incidente para la subordinada, distinción entre proposiciones regulares e irregulares y, a su vez, la subdivisión de las primeras en oblicuas, reflejas y recíprocas.

Como recogemos en el siguiente cuadro, el porcentaje de presencia de Salvá y Bello, de acuerdo con el canon explícito, es idéntico; sin embargo, el segundo gramático ejerce una influencia decisiva en la obra del colombiano, constituyendo como hemos dicho el canon implícito:

6 Obsérvese la cercanía con la caracterización de Bello (1988/ [1847-1860]): “460. El modo indicativo sirve para los juicios afirmativos o negativos, sea de la persona que habla, sea de otra persona indicada en la proposición de que dependa el verbo (...) 461. El indicativo se presta lo mismo a las proposiciones independientes que a las subordinadas" (p. 362). 
Tabla 2

Canon explícito en la obra de Santiago Pérez (1853)

\begin{tabular}{cccc}
\hline Ubicación de las citas & Martínez López & Salvá & Bello \\
\hline Portada & 1 & 1 & 1 \\
\hline Ejemplos & & 2 & $\begin{array}{c}\text { 2 ejemplos en verso } \\
\text { citados por Bello }\end{array}$ \\
\hline Porcentaje de citas & $14,28 \%$ & $42,85 \%$ & $42,85 \%$ \\
\hline
\end{tabular}

Fuente: Elaboración propia.

El tercer gramático de este segundo grupo es José de Urcullu, de origen vasco. Con una ideología liberal, tras la restauración de Fernando VII emigró a varios países, entre ellos Reino Unido y Portugal. Además de ejercer como traductor, fue autor de catecismos de diversas materias para su adopción en las escuelas, entre ellos de gramática, como el que nos ocupa ${ }^{7}$. Los publicó en Londres y también en Hispanoamérica (Fernández de Gobeo, 2020); el que constituye nuestro corpus se publicó, en efecto, en Bogotá en 1854.

Es una obra ligada a la tradición académica, a pesar de que también critica a la institución (a la que cita en cinco ocasiones) en el apartado de "Notas", incluido al final. Lo hace en relación con el leísmo, ya que defiende como error el uso del pronombre le por lo, algo que no ocurre, sostiene, en otras lenguas románicas como francés o italiano. También critica a la institución porque justifica como errores de imprenta el uso de lo en lugar de le por parte de Cervantes y de Granada, cuando según Urcullu ambos escritores fueron conscientes de la práctica errónea y quisieron corregirla. Este sería, pues, un caso de canon negativo. La obra, por otro lado, tiene una estructura erotemática.

Además de esta referencia a la Academia, solo encontramos como canon explícito los gramáticos de la Antigüedad y los de Port Royal, también en el apartado de notas, esta vez en relación con la cercanía entre el nominativo y el vocativo: "Los antiguos gramáticos los llamaban casos rectos (...). Varrón (...), los célebres filólogos de Port Royal,

7 Los catecismos eran una clase de obras que solían promover una enseñanza de tipo memorístico, como adoctrinamiento en una determinada materia, no solo la religiosa. En el siglo XIX en Colombia hubo una profusión de este tipo de obras en distintos ámbitos; además del gramatical de Urcullu, se publicaron catecismos de agricultura, de química, de geografía, de contabilidad, etc. (Guzmán Méndez et al., 2018). 
Regnien, Fromant y Gueroult han dado a los casos del nombre la misma colocación que se les da en este Catecismo" (Urcullu, pp. 154 y 155).

La Academia también está presente como canon implícito o encubierto en la terminología que utiliza para los tiempos verbales de la conjugación, en la que a diferencia del gramático precedente, no sigue a Bello: utiliza los términos presente de indicativo, pretérito imperfecto, pretérito compuesto, futuro y futuro compuesto.

El siguiente autor es Juan Vicente González, de origen venezolano, aunque la obra que analizamos, de 1857, fue publicada en Bogotá. Licenciado en Filosofía, se dedicó durante varios años a la política, primero como miembro del partido liberal y después del conservador, llegando a ser diputado y jefe del Cantón de Caracas. Fundó varios periódicos de corte político, entre ellos El Venezolano, El Diario de la tarde o El Heraldo. Como varios de nuestros gramáticos, comprometido con la educación, tras alejarse de la política fundó el colegio "El Salvador del Mundo" que, al parecer, gozó de cierto prestigio por la formación humanística recibida (EcuRed, 2020; Contreras, 2016).

En el propio título de la obra que analizamos, cuya estructura es erotemática, se hace referencia a Salvá: “Compendio de gramática española según Salvá y otros autores” (p. xx). Nosotros trabajamos con la séptima edición, que incluye la "Advertencia de la cuarta edición", en la que afirma que, desde que publicó la tercera edición, 6 años antes, se encontrarán notables cambios, nuevas reglas en que las prácticas de la lengua se explican con más sencillez y de forma más completa. Junto con ello, hace referencia a varios gramáticos, como recogemos en la siguiente síntesis de sus ideas:

- Elogio de Bello por encima de Salvá: afirma que en las sucesivas ediciones de su obra se había ido distanciando de Salvá y cuando estaba preparando una nueva edición se publicó la gramática de Andrés Bello.

- La gramática de 1847 de Bello es superior a muchas gramáticas de la Península, e incluso a las de otras naciones, pues no se pierde en "abstracciones ideológicas" ni en "caprichosas nomenclaturas" (p. 7).

- La terminología de Bello para los tiempos verbales es novedosa y coherente: inicialmente no la adoptó por no contradecir la seguida por los gramáticos de la Península, pero ahora lo considera ne- 
cesario, para así contribuir al abandono de la nomenclatura latina académica.

- Un nuevo caso de canon negativo lo encontramos en la crítica a la Academia debido a que desde 1796 no reforma su gramática según los últimos cambios, y se dedica solo a la ortografía.

- Crítica a la terminología de Salvá y de Martínez López por arbitraria. Reivindica la de Bello, que él adopta, como deberían hacer otros gramáticos españoles.

- En la ortografía sigue a la Academia.

Además de las referencias al canon explícito en esta "Advertencia a la cuarta edición", en distintos apartados de su obra recoge diversas citas, como exponemos en la Tabla 3, donde especificamos el número y el porcentaje con relación a la cifra total, que es 19:

Tabla 3

Canon explícito en la obra de Juan Vicente González (1857)

\begin{tabular}{lcccc}
\hline $\begin{array}{l}\text { Ubicación de } \\
\text { las citas }\end{array}$ & Academia & $\begin{array}{c}\text { Martínez } \\
\text { López }\end{array}$ & Salvá & Bello \\
\hline $\begin{array}{l}\text { Título } \\
\text { Prólogo }\end{array}$ & 2 & 1 & 3 & 6 \\
\hline Ortografía & 1 & & & 1 \\
\hline Morfología & & & 1 & 2 \\
\hline $\begin{array}{l}\text { Ejemplos } \\
\text { Porcentaje de }\end{array}$ & $15,78 \%$ & $5,26 \%$ & $26,31 \%$ & $\begin{array}{c}2 \text { ejemplos de } \\
\text { autores clásicos que } \\
\text { recoge Bello }\end{array}$ \\
\hline
\end{tabular}

Fuente: Elaboración propia.

Observamos que el gramático más citado es Bello, lo cual se corresponde con la influencia que ejerce en el tipo de análisis que desarrolla Juan Vicente González (1857). A lo largo de la obra, el influjo en la terminología es notable: en sintaxis habla, como Bello, de proposición incidente o subordinada y subdivide también la proposición regular transitiva en oblicua, refleja y recíproca. Por otro lado, constatamos que el análisis del verbo es muy similar, con una terminología idéntica y con explicaciones acerca del uso de las formas verbales muy similares. Además, varios ejemplos para ilustrar el uso de los tiempos son 
idénticos, aunque no afirme que los tome del gramático venezolano. Obsérvese, en particular, la explicación de las diferencias entre el antepresente y el pretérito:

De los tiempos compuestos de indicativo el ante-presente representa el atributo como anterior a una cosa que respecto al momento en que se habla, es presente; y por eso en este ejemplo: la Inglaterra SE HA НЕСHO señora del mar, se indica que aún dura el señorío del mar, mientras en Roma se hizo señora del mundo, el señorío del mundo se representa como una cosa que ya pasó: la forma compuesta tiene pues relación con algo que todavía existe (González, 1857, pp. 30 y 31) . $^{8}$

Junto con estos dos ejemplos, figura un tercero de Bello: "Los israelitas desobedecieron al Señor, que los había sacado de la tierra de Egipto" (p. 31).

Siguiendo con la terminología, también distingue entre subjuntivo común y subjuntivo hipotético, así como entre verbos desinentes y permanentes. Por último, reconoce que no ha adoptado el análisis de los verbos irregulares que hace Bello, lo que justifica por el carácter de su obra y por los destinatarios.

Constatamos, pues, que en la obra de Juan Vicente González (1857) las referencias explícitas a Bello son las más numerosas, lo que se corresponde también con que es el gramático principal en cuanto al canon implícito.

Afirma Jiménez Ángel (2018) que en el siglo XIX se fue viendo en Colombia un progresivo distanciamiento de las doctrinas de la RAE y de Salvá y un predominio de las de Bello, y aquí habría que situar a Juan Vicente González, que en 1849 había publicado tres ediciones de su Compendio, que siguió reimprimiéndose con el mismo título y que fue uno de los textos oficiales escolares en la Nueva Granada. En 1849 publicó la cuarta edición de su obra, en la que se distanciaba de Salvá

8 Obsérvese la cercanía con la afirmación de Bello (1988/ [1847-1860]): 639 (a). Comparando estas dos proposiciones: "Roma se hizo señora del mundo", y "La Inglaterra se ha hecho señora del mar", se percibe con claridad lo que distingue al pretérito del antepresente. En la segunda se indica que aún dura el señorío del mar; mientras que en la primera el señorío del mundo se representa como una cosa que ya pasó. La forma compuesta tiene pues relación con algo que todavía existe. 
y criticaba a la RAE por el modo en que había desarrollado la unidad ortográfica, además de criticar la gramática de Martínez López. Juan Vicente González elogia a Bello y dice que gracias a su obra había podido elaborar su Compendio (Garmendia Graterón, 2013; Rojas, 2007).

Observamos, pues, que en este segundo grupo de autores cuyas obras se publican a mediados del siglo XIX, si bien sigue presente la influencia de la Academia, en particular en José de Urcullu (1854), son dos los gramáticos que ejercen una notable influencia: Vicente Salvá, principalmente en Ulpiano González (1848), y Andrés Bello, que se manifiesta de forma clara en Santiago Pérez (1853) y en Juan Vicente González (1857).

\section{El análisis lógico en las gramáticas de mediados del siglo XIX}

Este tercer grupo está integrado por Zoilo Villar (1858) y José Belver (1859), ambos de origen colombiano. El primero, además de escritor y docente fue político del partido liberal y editor del periódico de esta ideología Instructor popular (Calderón, 2011). José Belver publicó varios textos escolares, entre ellos el que forma parte de nuestro corpus. Además, fundó en Colombia el colegio "Academia de la Paz" (Pérez Benavides, 2015).

Zoilo Villar (1858) y José Belver (1859) no hacen referencia al canon explícito, a excepción de una cita del primero al Diccionario de la Academia en el apartado de ortografía. García Folgado y Sinner (2013) defienden que las obras de ambos se inscriben en el análisis lógico, que se vio influido en Colombia principalmente por las figuras de Benedetti y de Martínez López. En este país esta corriente tuvo un peso mucho menor respecto de otros de Hispanoamérica como Argentina o Colombia (Zamorano Aguilar, 2010b) y, según defienden, ello fue debido a la influencia de la doctrina de Vicente Salvá, que rechazaba la gramática filosófica. El valenciano tuvo un importante peso en la enseñanza de esta materia en Colombia, sobre todo a partir de 1840, influencia que se vio favorecida por la propia legislación educativa (Arrázola, 1879, en García Folgado y Sinner, 2013).

En la obra de Villar (1858) encontramos varias consideraciones propias del análisis lógico, empezando por el prólogo, donde afirma 
que "para completar las explicaciones, en un libro destinado al análisis gramatical y lógico se da un repaso en el cual prácticamente se haga útil y positiva la enseñanza" (p. II y III). Asimismo, lo vemos en la caracterización del análisis gramatical, del que afirma que implica "descomponer, resolver las partes de un todo (...) y una a una las reconoceremos gramatical y lógicamente" (p. 62). Da importancia al razonamiento del alumno sobre los elementos lingüísticos; el análisis ha de servir para dar cuenta de la estructura del pensamiento. Junto con ello, en la terminología vemos influencia de este tipo de análisis, en particular al hablar de sujeto lógico y atributo lógico: "Es lógico todo sujeto que presenta un pensamiento determinativo o explicativo" (p. 86). Afirma que "una proposición puede ser lógica o gramatical. Será lógica siempre que lógico se presente el sujeto o el atributo; y será gramatical si gramaticales fuesen el atributo o el sujeto" (p. 79). Esta doble perspectiva lógica y gramatical es, efectivamente, propia de la gramática filosófica (Calero Vaquera, 2009, p. 27).

Sobre Villar afirman García Folgado y Sinner (2013) que incorporó, no obstante, junto con el análisis filosófico, las doctrinas de Salvá, Bello y la Academia. En efecto, el influjo del gramático venezolano es claro, en particular en el análisis que desarrolla del verbo, ya que no solo manifiesta influencia la caracterización de los tiempos verbales, sino que recoge varios ejemplos idénticos a los de Bello, sin hacer referencia alguna a la procedencia. La distinción entre el pretérito perfecto compuesto y el simple es muy similar a la del venezolano, que también hemos visto en Juan Vicente González (1857), así como la de otros tiempos, aun cuando la terminología que utiliza para referirse a las formas de la conjugación es distinta. A ello podemos sumar la caracterización del presente como tiempo que "significa la coexistencia del atributo con el modo en que proferimos el verbo" o la del pretérito imperfecto, al que denomina pretérito coexistente, como aquel que "significa la coexistencia del atributo con una cosa pasada", caracterización que recuerda a la Bello, si bien la terminología es propia de Salvá.

Respecto de José Belver (1859), tal y como se indica en la página de créditos de la obra, donde se refiere a la concesión del derecho de publicación, es en realidad una parte de otra más amplia del autor a la que no hemos podido tener acceso, titulada Compendio de la gramática de Don Vicente Salvá, puesta al alcance de los niños de la primera 
edad, notablemente reformado y adicionado con un capitulo sobre el análisis lógico de la proposición, para uso de los alumnos del Colegio de la Paz. Si tenemos en cuenta que en la gramática filosófica se desplaza el foco de interés de la gramática a la oración, proposición, frase o período (Calero Vaquera, 2009), no resulta extraño que José Belver dedique 25 páginas de su obra al "Análisis lógico de la proposición", a lo que añade como subtítulo "Introducción indispensable al estudio razonado de la gramática” (p.xx). Respecto del contenido, afirman García Folgado y Sinner (2013) que se estudian las partes de la proposición desde una concepción tripartita (sujeto, verbo-cópula, atributo), aunque "no aborda la dualidad proposición/juicio ni entra a detallar los tipos de complemento o abunda en la tipología proposicional" (p. 117). Además, destacan que esta obra debió de tener cierta repercusión, pues aparece en el Proyecto de ley de 1859 del Estado de Cundinamarca.

Como probablemente ocurrió en Colombia, la difusión del análisis lógico en España se vio favorecida por su enseñanza en las escuelas (Calero Vaquera, 2008) aunque, como hemos indicado, este análisis no gozó en aquel país de gran expansión en el siglo XIX y, en el caso de nuestro corpus, se manifiesta exclusivamente en la obra de dos autores de textos escolares.

\section{La doctrina de Bello en las gramáticas de las últimas décadas del siglo XIX}

Las obras de César Guzmán (1872) y de Jorge Roa (1889) forman parte de este cuarto grupo en el que el gramático que ejerce mayor influencia es Bello. El primer autor es de origen colombiano, nacido en Cundinamarca, y fue director de instrucción pública primaria, además de trabajar como traductor y de ejercer la labor de cónsul, que lo llevó a vivir en París durante un tiempo. La obra que analizamos, de 1872, fue adoptada desde su publicación como texto oficial en las escuelas colombianas (Castro Gómez et al., 2007; Guzmán Méndez et al., 2018).

Por lo que respecta al canon explícito, apenas aparecen referencias en esta obra: no se cita ni a la Academia ni a Salvá; Bello figura en un ejemplo y en dos ocasiones: al hablar de la lengua como expresión de los pensamientos y al defender la ausencia de casos en español. Se refiere la novedad que supone la obra del venezolano, frente a las gramáticas latinizantes, que conducen a error: 
Para los alumnos que no han estudiado por otra gramática que la de Bello, la declinación de los pronombres no presenta dificultad alguna; pero para los que hayan formado las primeras nociones gramaticales según las doctrinas de ciertos autores latinizantes, pueden ofrecerse desde luego motivos de confusión (p. 87).

Tras esta afirmación, recoge de manera íntegra la Nota VI. Declinación de la Gramática de Bello, en la que explica la necesidad de distinguir entre casos y complementos, y justifica la presencia de casos en español exclusivamente para el pronombre. En esta cita Bello defiende su postura y afirma que "Aquí hasta la lengua latina abandona a los latinizantes" (p. 94).

Frente a otros gramáticos de nuestro corpus que, a pesar de manifestar influencia de Bello en sus obras, siguen manteniendo la existencia de casos, en Guzmán (1872) observamos una firme decisión, siguiendo al venezolano, de romper con la tradición previa latinizante. Junto con ello, la influencia del gramático en el análisis que presenta del verbo es clara, algo que hemos visto en otros autores que lo preceden en el corpus. Utiliza la misma terminología para los tiempos simples y los compuestos, además de caracterizar su significado siguiendo también al gramático.

Jorge Roa (1889), el autor de la última obra del corpus, es de origen colombiano, nacido en Cali. Fue docente, poeta, literato, editor y político (Pineda Cupa, 2017); ocupó distintas carteras ministeriales e incluso fue nombrado ministro en España durante el reinado de Alfonso XIII (Murillo Sandoval, 2017; Rodríguez Guerrero, 1969).

Su obra, de 1889 (quinta edición), como se indica en la portada, fue adoptada por las escuelas primarias de Colombia. Él mismo había hecho una propuesta en 1887 al Ministerio de Instrucción Pública para su adopción como texto, de la que recibió el informe favorable, lo cual contribuyó a su difusión, al ser utilizado como texto durante varios años en las escuelas colombianas.

En el prólogo, escrito por D. R. Guzmán, se afirma que sigue la gramática de la Academia y en algunos aspectos también la de Bello. Por otra parte, el propio autor hace referencia explícita a la terminología de los tiempos verbales adoptada por la Academia y por Bello, e incluye ambas. Deja a criterio del profesor la enseñanza de las dos, que sería desde luego, un beneficio para los estudiantes: 
Los nombres de los tiempos según la Gramática de la Academia Española, son como sigue: presente, pretérito perfecto (PRETÉRITO) (...), pretérito imperfecto (COPRETÉRITO) (...). Dejamos al juicio del maestro el discernir si los alumnos pueden aprender ambas nomenclaturas, pues deben hacerlo siempre que esto no ocasione confusión alguna (Roa, 1889, p. 36, nota a pie).

Si bien la influencia de Andrés Bello en Roa es notable, no aparece más referencia al gramático que la del prologuista, por lo que estamos ante un nuevo caso de canon implícito. Sí cita, sin embargo, a la Academia en dos ocasiones. Rodríguez Guerrero (1969) afirma que su Curso elemental está "calcado en las doctrinas y los procedimientos de Bello"; constatamos su influencia, sin que lleguemos a considerar el extremo que defiende esta estudiosa. El autor habla de casos, pero al definirlos, se refiere solo al pronombre, como ya vimos que hacía Bello. Obsérvese la diferencia en este tema entre los gramáticos del primer grupo que hemos distinguido, ligados a la tradición latina y defensores de la existencia de casos en español, y los de este cuarto grupo. Además, como Bello, Roa distingue entre oración y proposición. Por otro lado, nuevamente es muy clara la influencia en el verbo: utiliza su terminología para los tiempos, aunque como hemos visto, también la académica. No figuran, sin embargo, los ejemplos sobre el uso de las formas de Bello, como sí hemos visto en otros gramáticos?.

Así pues, quedan establecidas las cuatro etapas en la enseñanza de la gramática española en Colombia.

\section{Resultados y conclusiones}

Hemos comprobado que hay una evolución teórico-metodológica en las gramáticas publicadas en Colombia durante el siglo XIX, de modo que, de acuerdo con los objetivos que nos proponíamos al inicio del trabajo, hemos establecido una periodización en la enseñanza de la gramática del español a lo largo del siglo, que recogemos a modo de síntesis en la Tabla 4.

9 Como hemos demostrado, la influencia de Bello en varios autores del corpus es manifiesta. La estela del venezolano, no obstante, no fue uniforme en los distintos gramáticos de Hispanoamérica; en varios países la influencia del gaditano Eduardo Benot, entre otros, fue superior (Zamorano Aguilar, 2017). 
Tabla 4

Periodización enseñanza de la gramática en Colombia (siglo XIX)

\begin{tabular}{|c|c|c|c|c|}
\hline & Grupo I & Grupo II & Grupo III & Grupo IV \\
\hline Período & $\begin{array}{l}\text { Primeras } \\
\text { décadas siglo } \\
\text { XIX }\end{array}$ & $\begin{array}{l}\text { Mediados del } \\
\text { siglo }\end{array}$ & $\begin{array}{l}\text { Primeros años } \\
\text { de la segunda } \\
\text { mitad del siglo }\end{array}$ & $\begin{array}{l}\text { Últimas } \\
\text { décadas del } \\
\text { siglo }\end{array}$ \\
\hline $\begin{array}{l}\text { Características } \\
\text { fundamentales } \\
\text { respecto del } \\
\text { canon }\end{array}$ & $\begin{array}{l}\text { Influencia } \\
\text { académica } \\
\text { Tendencia } \\
\text { latinizante }\end{array}$ & $\begin{array}{l}\text { Transición } \\
\text { entre doctrinas } \\
\text { tradicionales y } \\
\text { concepciones } \\
\text { más recientes } \\
\text { de la gramática } \\
\text { Influencia } \\
\text { académica, } \\
\text { de Salvá y de } \\
\text { Bello }\end{array}$ & $\begin{array}{l}\text { Análisis lógico } \\
\text { Influencia } \\
\text { doctrinas } \\
\text { de Salvá, } \\
\text { Martínez } \\
\text { López y Bello }\end{array}$ & $\begin{array}{l}\text { Predominio de } \\
\text { la influencia } \\
\text { de Bello }\end{array}$ \\
\hline Gramáticos & $\begin{array}{l}\text { Santiago } \\
\text { Arroyo (1826) } \\
\text { Anónimo } \\
(1833)\end{array}$ & $\begin{array}{l}\text { Ulpiano } \\
\text { González } \\
\text { (1848) } \\
\text { Santiago Pérez } \\
\text { (1853) } \\
\text { José de Urcullu } \\
\text { (1854) } \\
\text { Juan Vicente } \\
\text { González } \\
\text { (1857) }\end{array}$ & $\begin{array}{l}\text { Zoilo Villar } \\
\text { (1858) } \\
\text { José Belver } \\
(1859)\end{array}$ & $\begin{array}{l}\text { César Guzmán } \\
(1872) \\
\text { Jorge Roa } \\
(1889)\end{array}$ \\
\hline
\end{tabular}

Fuente: Elaboración propia.

De lo expuesto a lo largo del trabajo se deriva que no se trata de cuatro grupos cerrados, sino que existen conexiones entre ellos, como lo demuestra que en tres estén presentes las doctrinas de Salvá y/o de Bello. Por otro lado, queremos destacar el avance científico que supone este trabajo con el establecimiento de una periodización en la enseñanza de la gramática española en Colombia.

A lo largo del siglo, se fue produciendo un distanciamiento de las doctrinas de Salvá y de la Academia y un predominio de la de Bello (Jiménez Ángel, 2018). Según defendemos, el hecho de que las obras que manifestaban la influencia del venezolano fueran adoptadas en las escuelas también contribuyó a una mayor presencia del gramático.

Añadimos aquí respecto de Bello que la influencia que ejerció durante la segunda mitad del siglo no fue similar en Colombia y en buena parte de Hispanoamérica respecto de España, como ha demostrado Calero Vaquera (2000), quien defiende que pudieron haber influido en 
ello causas políticas, como su nacionalidad venezolana y la reciente independencia de los países hispanoamericanos. Sostiene la estudiosa que esta situación cambió en España a partir de la última década del siglo XIX, cuando Bello empezó a ser citado con frecuencia y su gramática fue ampliamente conocida.

A partir de aquí, continuaremos nuestra investigación en futuros trabajos con el análisis de otros temas de morfología y de sintaxis en Colombia durante el siglo XIX, con los que esperamos una nueva confirmación de la existencia de las cuatro tendencias analizadas.

\section{Referencias bibliográficas}

Agudelo Gil, M. G. (14-19 de julio de 2014). La enseñanza de la gramática en Colombia: un asunto pluricontextual. Comunicación presentada en el XVII Congreso Internacional de la Asociación de Lingüística y Filología de América Latina (ALFAL), João Pessoa. Paraíba, Brasil.

Anónimo (1833). Elementos de gramática castellana para uso de los niños que concurren a las escuelas, dispuestos en forma de diálogo. Para la mejor instrucción de la juventud. Tipografía Tormentaria por J. M. Angulo.

Arrázola, A. M. (1879). Memorándum bibliográfico de gramática española. Segundo grado del estudio general del idioma. Francisco Torres Amaya.

Arroyo, S. (1826). Gramática y ortografía de la lengua castellana. Para el uso de los niños de las escuelas de primeras letras del departamento del Cauca. Por un amigo de la buena educación. Imprenta de Espinosa, por Valentín Molano.

Bello, A. (1988/ [1847-1860]. Gramática de la lengua castellana destinada al uso de los americanos. Con las notas de Rufino José Cuervo. Ed. Ramón Trujillo. (Vol. 2). Arco Libros.

Belver, J. (1859). Análisis lójico de la proposición. Introducción indispensable al estudio razonado de la gramática. Imprenta de J. U. Leiva.

Brekle, H. E. (1986). What is History of Linguistics and to what end is it produced? A didactic approach. En T. Bynon y F. R. Palmer (Eds.), Studies in the history of Western Linguistics: In honour of R. H. Robins (pp. 1-10). Cambridge University Press. 
Calderón, D. F. (2011). Economía política y educación liberal en el Estado de Santander. Gestión y Región, (11), 63-78. https:// dialnet.unirioja.es/servlet/articulo?codigo $=7402739 \&$ orden $=0$ \&info $=$ link

Calero Vaquera, M. L. (2000). La recepción de Bello en las gramáticas españolas del XIX. En C. Schmitt y N. Cartagena (Eds.), Actas del congreso-homenaje celebrado con motivo del ciento cincuenta aniversario de la Gramática de la Lengua Castellana destinada al uso de los americanos (pp. 1-20). Romanistischer Verlag.

Calero Vaquera, M. L. (2007). Desarrollo de la sintaxis en la tradición gramatical hispánica. En J. Dorta, C. Corrales y D. Corbella (Eds.), Historiografía de la lingüistica en el ámbito hispánico. Fundamentos epistemológicos y metodológicos (pp. 89-118). Arco/Libros.

Calero Vaquera, M. L. (2008). Análisis lógico y análisis gramatical en la tradición española: hacia una (r)evolución de la sintaxis. En M. A. Maquieira Rodríguez y M. D. Martínez Gavilán (Eds.), Gramma-temas 3: España y Portugal en la tradición gramatical (pp. 11-42). Universidad de León, Centro de Estudios Metodológicos e Interdisciplinares.

Calero Vaquera, M. L. (2009). Lo que la sintaxis debe a la filosofía. En M. Veyrat Rigat y E. Serra Alegre (Eds.), La lingüística como reto epistemológico y como acción social. Estudios dedicados al profesor Ángel López García con ocasión de su sexagésimo aniversario (pp. 25-36). Arco Libros.

Cardona, P. (2007). La Nación de papel. Textos escolares, lectura y política. Estados Unidos de Colombia 1870-1876. Fondo Editorial Universidad EAFIT.

Castro Gómez, S., Hoyos Vásquez, G., y Millán de Benavides, C. (Eds.) (2007). Pensamiento colombiano del siglo XX. Editorial Pontificia Universidad Javeriana.

Contreras, N. de J. (2016). Los héroes en la historiografía romántica de Juan Vicente González. Revista Politeia, 56(39), 69-102. https://www.redalyc.org/pdf/1700/170056019003.pdf

EcuRed (2020). Juan Vicente González. https://www.ecured.cu/Juan_ Vicente_Gonz\%C3\%Allez

Fernández de Gobeo, N. (2020). José de Urcullu (¿1790?-1852). En M. Alvar Ezquerra (Ed.), Biblioteca Virtual de la Filología 
Española (BVFE): directorio bibliográfico de gramáticas, diccionarios, obras de ortografía, ortología, prosodia, métrica, diálogos e historia de la lengua. https://www.bvfe.es/ autor/10808-urcullu-jose-de.html.

García Folgado, M. J. (2007). La gramática española y su enseñanza entre dos siglos: Diego Narciso Herranz y Quirós. Moenia, (13), 385-99. http://hdl.handle.net/10347/6078

García Folgado, M. J. y Sinner, C. (2013). Apuntes sobre el análisis lógico y gramatical en Colombia en el siglo XIX. En S. Große, A. Hennemann, K. Plötner, y S. Wagner (Eds.), Angewandte Linguistik. Linguistique appliquée. Zwischen Theorien, Konzepten und der Beschreibung sprachlicher Äußerungen. Entre théories, concepts et la description des expressions linguistiques (pp. 109-120). Peter Lang.

Garmendia Graterón, O. J. (2013). Cuatro textos escolares de gramática en la historia de la educación en Venezuela (1820-1930). Teorías, Enfoques y Aplicaciones en las Ciencias Sociales, TEACS, 5(12), 119-134. https://revistas.uclave.org/index.php/teacs/ article/view/1619

Garrido Vílchez, G. B. (2010). Las gramáticas de la Real Academia Española: teoría gramatical, sintaxis y subordinación (18541924). Ediciones de la Universidad de Salamanca.

Gómez Asencio, J. J. (2014). La sintaxis en gramáticas españolas de 1770 a 1854: tratamientos, modelos y ámbitos de estudio. En F. San Vicente, A. L. Hériz y M. E. Pérez Vázquez (Eds.), Perfiles para la historia y crítica de la gramática del español en Italia: siglos XIX y XX. Confluencia y cruces de tradiciones gramaticográficas (pp. 61-92). Bononia University Press.

González Corrales, L. (2020). Santiago Arroyo (1773-1845). En M. Alvar Ezquerra (Ed.), Biblioteca Virtual de la Filología Española (BVFE): directorio bibliográfico de gramáticas, diccionarios, obras de ortografía, ortología, prosodia, métrica, diálogos e historia de la lengua. https://www.bvfe.es/autor/23587arroyo-santiago.html

González, J. V. (1857). Compendio de gramática castellana según Salvá $i$ otros autores. Oficina de El Neo-granadino.

González, U. (1848). Observaciones curiosas sobre lengua castellana o sea manual práctico de la gramática de dicha lengua. Imprenta de José A. Cualla. 
Guzmán Méndez, D. P., Marín Colorado, P. A., Murillo Sandoval, J. D., y Pineda Cupa, M. A. (Eds.) (2018). Lectores, editores y cultura impresa en Colombia: siglos XVI-XXI. Universidad de Bogotá de Jorge Tadeo Lozano.

Guzmán, C. C. (1872). Composición y gramática práctica para las escuelas primarias. Imprenta de Gaitán.

Jiménez Ángel, A. (2018). Ciencia, lengua y cultura nacional. La transferencia de la ciencia del lenguaje en Colombia (1867-1911). Pontificia Universidad Javeriana.

Lliteras, M. (1992). La teoría gramatical de Vicente Salvá. Sociedad General Española de Librería.

Martínez-Atienza, M. (en prensa a). La concepción de la gramática en Colombia durante el siglo XIX. Boletín de Filología, 56(2).

Martínez-Atienza, M. (en prensa b). El tratamiento de la sintaxis en la Colombia del siglo XIX. Rilce. Revista de Filología Hispánica.

Michael, I. (1970). English grammatical categories and the tradition to 1800. Cambridge University Press.

Murillo Sandoval, J. D. (2017). Semblanza de Jorge Roa (1858-1927). Edired. http://www.cervantesvirtual.com/obra/jorge-roacali1858-madrid1927-semblanza-783344/

Orlando Melo, J. (2006). El texto en la escuela colombiana: unas notas breves y una modesta propuesta. http://www.jorgeorlandomelo.com/texto_en_la_escuela.htm

Peñalver Castillo, M. (1992). Las ideas gramaticales de Vicente Salvá. En M. Ariza Viguera, R. Cano-Aguilar, J. Mendoza, y A. Narbona (Eds.), Actas del II Congreso Internacional de Historia de la Lengua española (vol. 1, pp. 739-746). Pabellón de España.

Pérez Benavides, A. C. (2015). Nosotros y los otros. Las representaciones de la nación y sus habitantes. Colombia 1880-1910. Pontificia Universidad Javeriana.

Pérez, S. (1853). Compendio de gramática castellana. Imprenta del Neo-granadino.

Pineda Cupa, M. Á. (2017). Jorge Roa y la librería nueva: antecedentes $\mathrm{y}$ aspectos esenciales sobre el editor colombiano a finales del siglo XIX. Lingüistica y Literatura, 38(71), 109-130. https:// doi.org/10.17533/udea.lyl.n71a06

Ridruejo, E. (1985). El tratamiento de los modos verbales en la Gramática de la lengua castellana de V. Salvá. En Miscellània 
Sanchis Guarner (vol. 2, pp. 263-268). Universidad de Valencia.

Roa, J. (1889). Curso elemental de gramática castellana. Librería colombiana.

Rodríguez Guerrero, I. (1969). Libros colombianos raros y curiosos. Boletín Cultural y Bibliográfico, 12(11), 50-58. https://publicaciones.banrepcultural.org/index.php/boletin_cultural/ article/view/3813

Rojas, F. J. (2007). Gramática y clases de palabras en la lingüistica venezolana del siglo XIX. Universidad Católica Andrés Bello.

Salvá, V. (1988/ [1830-1847]. Gramática de la lengua castellana. Estudio y edición de Margarita Lliteras (Vol. 2). Arco Libros.

Urcullu, J. (1854). Catecismo de gramática castellana. Aumentada con la ortografía y prosodia, para el uso de la juventud. Imprenta de Fco. Torres Amaya.

Uzcátegui, R. (2010). Educación y Escuela en las leyes de España, Colombia y Venezuela entre 1810-1830. Sapiens. Revista universitaria de investigación, 11(1), 169-195.

Villar, Z. (1858). Elementos de gramática de la lengua castellana para la enseñanza de la juventud. Imprenta de Villar.

Zamorano Aguilar, A. (2010a). “Teoría del canon y gramaticografía. La tradición española de 1750 a 1850. En V. Gaviño Rodríguez y F. Durán López (Eds.), Gramática, canon e historia literaria (1750 y 1850) (pp. 421-466). Visor Libros.

Zamorano Aguilar, A. (2010b). Análisis lógico y análisis gramatical en Colombia (s. XX): la teoría lingüística de Próspero González Ruiz. Revista argentina de historiografía lingüística, 22, 125-143. http://www.rahl.com.ar/index.php/rahl/article/ view/29

Zamorano Aguilar, A. (2012). Teoría del caos e historiografía de la lingüística. Una interpretación. Beiträge zur Geschichte der Sprachwissenschaft, 22, 243-298.

Zamorano Aguilar, A. (2017). Incursión en las fuentes de la teoría gramatical latinoamericana (primer tercio del siglo XX): el estatuto canónico de Andrés Bello y la Real Academia Española. En R. Bein, J. E. Bonnin, M. Di Stefano, D. Lauria, M. C. Pereira (Coords.), Homenaje a Elvira Arnoux. Estudios de análisis del discurso, glotopolítica y pedagogía de la lectura y 
Panorama y canon en la enseñanza de la gramática española en Colombia | Martínez-Atienza

la escritura Tomo II: Glotopolítica (pp. 299-317). Editorial de la Facultad de Filosofía y Letras de la Universidad de Buenos Aires. 